\title{
Ensino interativo de língua portuguesa: teoria, prática e aplicação
}

\author{
Maria Cristina Parreira da Silva \\ UNESP - Universidade Estadual Paulista (SJRP) \\ Rosimar de Fátima Schinelo \\ FATEC - Catanduva-SP
}

\begin{abstract}
Resumo
Considerando língua e linguagem inerentes ao ser humano e base da interação, delineia-se atualmente a necessidade de um ensino que se diferencie das práticas tradicionais de leitura e redação. A forma metodológica utilizada pelo profissional quando propõe atividades em seu trabalho resulta na dificuldade da interação entre o ensino de língua materna (LM) e a vivência do aluno com sua própria língua. Neste relato, propomos que o ensino da LM deve se realizar de forma edificadora, incitando o aluno a desempenhar suas interações socioculturais e profissionais.

Palavras-chave: ensino/aprendizagem; língua materna; concepções de linguagem; português para fins específicos.
\end{abstract}

\begin{abstract}
Considering language and its use as being inherent to the human being and the basis for interaction, there is a current view that teaching needs to be differentiated from the traditional practices of reading and writing. It is thought that the methodological approach used by teachers when they propose activities in school results in a negative interaction between the teaching of mother tongue and the experiences of students with their own language. In this report, we propose that the teaching of the mother tongue should encourage students to interact socioculturally and professionally.
\end{abstract}

Keywords: Teaching and learning; mother tongue; language conceptions; Portuguese for specific purposes

\section{INTRODUÇÃO}

Enquanto alunas, professoras e pesquisadoras na área de ensino e linguagem, sempre tivemos como meta relacionar as teorias apre(e)ndidas no decorrer de nossa formação acadêmica e as práticas vivenciadas no cotidiano do ensino-aprendizagem de Língua Materna (LM) e estrangeira (LE). 
Duas situações sempre foram um ponto de questionamento em nossa prática cotidiana. A primeira delas diz respeito a um ensino voltado apenas para a metalinguagem gramatical, desvinculando assim o sujeito de sua própria língua, ou seja, a língua ensinada torna-se alvo de ressentimento como se fosse impossível dominá-la.

Dentro desse aspecto, há que se considerar que toda criança aprende de maneira natural a língua de sua comunidade linguística; assim, quando ela chega à escola, já tem grande domínio das habilidades interativas e está aberta a compartilhar de todo conhecimento veiculado pela instituição escolar; no entanto, o abandono escolar ou a permanência por vários anos na escola sem aprovação (mesmo que incluído na progressão continuada) é um lamentável índice estatístico. Sob essa ótica, podemos considerar que, dentre outros fatores, o distanciamento entre a língua que o aluno domina e aquela que a escola ensina é responsável pela tão comentada frustração escolar. Acreditamos que, apesar de as práticas escolares não enfocarem a relação língua-sociedade, todo ensino acontece para um determinado fim.

A segunda situação tem que ver com um sistema escolar incapaz de responder à pergunta mais frequente nas salas de aula: "Professor, onde, quando e para que eu vou usar isso?”. A questão não tem sido respondida e os alunos permanecem decorando regras, tendo dificuldade para contextualizá-las.

Alguns profissionais, ao perceberam essa carência, criaram, amparados por teorias linguísticas, novas estratégias de ensino que proporcionem ao aluno a aproximação entre os conceitos teóricos e o uso efetivo da linguagem. Nesse sentido, muitos cursos foram criados com o intuito de propor atividades voltadas para fins específicos, tanto para LM quanto para LE.

O relato que apresentaremos insere-se na temática "ensino e linguagem" partindo de um breve histórico das concepções linguísticas e culminando na descrição das atividades práticas realizadas.

\section{A TEORIA A SERVIÇO DA PRÁTICA}

O domínio de algumas concepções de linguagem e de linguística são essenciais para compreender a dimensão da importância de um ensino eficaz tanto nos primeiros anos escolares quanto na formação especializada. Em relação a isso, lemos em Genouvrier \& Peytard (1974) sobre a adequação do ensino da gramática para os vários níveis de aprendizagem: “aquém da gramática”, “a gramática” e “além da gramática”. 
Isso significa que, nos primeiros anos de aprendizagem, os alunos podem e devem trabalhar sem a metalinguagem tradicional e, em seguida, quando já adquiriram um raciocínio com maior grau de abstração, podem apre(e)nder a metalinguagem para depois serem trabalhados os conceitos de linguística propriamente ditos.

Estudiosos da linguagem e educadores observam que a abstração da metalinguagem escolar, quando sobreposta à abstração do processo de escrita, tem de certa forma distanciado os escritores/leitores de sua própria língua, ou porque eles não compreendem o processo de escrita ou porque sua relação com a escrita torna-se uma relação metalinguística, distante de todo aspecto sócio-cultural peculiar à língua de cada falante. Nessa perspectiva, temos muitos professores que não respondem à pergunta “para que ensinar Língua Portuguesa” e sabemos que a resposta envolve, segundo Geraldi (2000), tanto uma concepção de linguagem como uma postura em relação à educação. Para o autor, três concepções podem ser apontadas:

1. A linguagem é a expressão do pensamento - estudos tradicionais;

2. A linguagem é instrumento de comunicação - teoria da comunicação;

3. A linguagem é uma forma de “inter-ação” - teoria linguística.

É na terceira concepção que nos pautamos como professoras, por acreditarmos que o ensino de LM deve estabelecer uma ação interativa que faça de seus falantes sujeitos capazes de se constituírem nesse espaço social e histórico. É partindo dessa concepção que afeta autor/texto/leitor que gostaríamos de considerar os apontamentos que seguem.

Um aspecto que escapa muitas vezes ao professor inexperiente é o fato de que o aluno já chega à escola falando uma variante da língua portuguesa e que a escola, com a ambição de ensinar a língua padrão, esquece-se de considerar todo um mundo de conhecimentos prévios internalizados pelos alunos, tentando apagar tudo que classifica como "errado".

A escola peca por desconsiderar as variantes linguísticas existentes na língua, decorrentes de diferenças geográficas, sociais, educacionais. Esse fato muitas vezes intensifica um dos preconceitos mais velados que enfrentamos e que não é passível de sanção legal: o “preconceito linguístico”, que segundo Bagno (2008, p.19) “está ligado, em boa medida, à confusão que foi criada no curso da história, entre língua e gramática normativa.”. O autor, ao pensar nos entraves que ainda excluem as variantes linguísticas da sala de aula, arrola alguns mitos que permeiam nosso imaginário sobre nosso idioma. Dentre eles, a questão da unidade da língua, de que o brasileiro não sabe 
falar português, de que português é difícil e de que se deve falar como se escreve, por exemplo. No primeiro capítulo do livro de Silva (2004), há também uma crítica a essa ideia de que o português "vai mal” no Brasil.

A Gramática Normativa, utilizada como imposição de verdades absolutas, restringe as possibilidades de diálogo com a língua viva, em movimento, dinâmica e constitutiva de todos os falantes. Estudar os fenômenos pragmáticos é muito mais interessante e enriquecedor que fazer análise sintática de determinados textos, cuja resposta vem pronta no livro do professor. Se admitirmos as várias possibilidades ou mesmo somente o questionamento como exercício, certamente melhores resultados serão obtidos. Para tanto é necessário além de uma formação aprofundada do professor, que ele não espere uma receita pronta de um pesquisador e sim que proceda a uma mudança de perspectiva na concepção de língua e do ensino de LM na escola, como diz Possenti (2002).

À medida que o aluno estabelece esse processo interativo, em que seu conhecimento linguístico é o fundamento para a aplicação da língua portuguesa nas práticas discursivas, efetiva-se o que, na teoria da enunciação, caracterizamos como o diálogo estabelecido entre o eu /autor/ e o tu /leitor/ (Benveniste, 1995) nos meandros de um contexto:

A linguagem só é possível porque cada locutor se apresenta como sujeito, remetendo a ele mesmo como eu no seu discurso. Por isso, eu propõe outra pessoa, aquela que, sendo embora exterior a "mim", torna-se o meu eco [...] A polaridade das pessoas é na linguagem a condição fundamental, cujo processo de comunicação, de que partimos, é apenas uma consequência totalmente pragmática. (Benveniste, 1995, p.286)

É reconhecendo esse espaço entre o eu e o outro que se torna possível para o professor de LM trabalhar com a vivacidade da língua, lugar de constituição de sentidos, e não com a falsa estaticidade linguística abordada por concepções que imobilizam pensamentos críticos e preenchem os espaços abertos para o conhecimento.

Para Bakhtin (1997), toda linguagem é, na sua essência, dialógica, seja ela cotidiana, prática, artística ou científica. E essa dialogicidade se faz no universo extralinguístico, considerando-se que “a linguagem só vive na comunicação dialógica daqueles que a usam”.

Um ensino eficiente da LM seria então aquele que abre espaço para o outro: outros dizeres, outros pensares, outros sentidos que se fazem no percurso instaurado 
entre o fazer cotidiano e a prática da sala de aula. Conforme afirma Silva, após analisar alguns itens das Diretrizes:

Essa pedagogia voltada para o todo da língua e não para algumas de suas formas, decerto socialmente privilegiadas, levará o indivíduo a, desde o momento em que começa a refletir sobre a língua - o que se processa desde a alfabetização -, ter consciência de que sabe falar a língua que fala todo dia, mas que precisa saber mais sobre ela e que esse saber pode crescer com ele por toda sua vida. (SILVA, 2004, p.35)

\section{RELATO DE PRÁTICAS DIDÁTICO-PEDAGÓGICAS}

Pensando nas dificuldades que as pessoas encontram em usar a LM como ferramenta do fazer cotidiano, desenvolvemos propostas de cursos que aproximassem nosso conhecimento teórico e a necessidade imediata de interação pessoal e profissional dos alunos.

O trabalho realizado desenvolveu-se em empresas de São José do Rio Preto, SP, e a primeira experiência ocorreu no Serviço Social do Comércio, em 2006, com o curso Desvendando os mistérios da linguagem (duração de 32 horas), em que foram trabalhados os seguintes temas: "Lendo e redigindo além das palavras”; "Leitura e produção escrita - do papiro à Internet”; “Gramática - quando e como ensinar?”; "Preconceito linguístico e ensino"; “Aprimoramento pessoal e profissional”; “Mesclando linguagens”; “Encantando alunos” e "Para textualizar é só começar”.

A oficina teve como público-alvo professores interessados em despertar seu potencial pessoal e profissional para o trabalho com leitura e produção de textos, adequando-os às necessidades da vida quotidiana de seus alunos. Inscreveram-se para as atividades, no entanto, profissionais de diferentes áreas, tais como: agrônomo, psicólogo, pedagogos, publicitários, professores aposentados e professores em formação. Esse fato foi uma rica contribuição que possibilitou compartilhar conhecimentos.

Os encontros tiveram como objetivo sensibilizar os participantes a desenvolver um trabalho com a leitura e a escrita de forma consciente e crítica. A participação conjunta propiciou uma interpretação crítica de textos para o desempenho de várias atividades, tanto pessoais quanto profissionais. Ao ampliar a visão de mundo e aumentar seus conhecimentos sobre a língua e linguagem, os participantes: i) se tornaram mais aptos a engendrar em seu cotidiano o gosto pela leitura e produção de textos; ii) aprenderam a aplicar de forma consciente as regras gramaticais e a usar os 
materiais de consulta; iii) adquiriram o respeito pela variação linguística; e iv) obtiveram conhecimentos dos vários gêneros e suportes.

O planejamento de cada encontro compreendeu o desenvolvimento dos seguintes tópicos: “o que utilizar”, “para que utilizar”, “para quem utilizar”, “como utilizar” e “transpondo degraus”. Na metodologia de trabalho, foram utilizados vários recursos, dentre eles: músicas, imagens e fotografias, vídeos, poesias, livros didáticos e periódicos. Os participantes tiveram a oportunidade também de realizar leituras não convencionais, por meio de objetos ofertados que instigavam o uso dos cinco sentidos para a percepção do texto. Como resultado, em cada encontro, textos dos mais diversos tipos eram elaborados, tanto orais quanto escritos, de forma que a criatividade e a liberdade de se constituírem como autores fossem o objetivo final. A experiência vivenciada nesse grupo de trabalho foi profícua para os participantes e ultrapassou os limites da sala de aula. Entre os relatos, podemos citar, no quadro abaixo, algumas apreciações e sugestões apresentadas na avaliação realizada no último encontro:

\begin{tabular}{|c|c|}
\hline Apreciações & Relatos e Sugestões \\
\hline $\begin{array}{ll}\text { O curso } \\
\checkmark & \text { foi relevante para a vida pessoal e profissional; } \\
\checkmark & \text { contribuiu para a vida escolar ; } \\
\checkmark & \text { foi responsável pela descoberta da importância } \\
& \text { da leitura para ampliação de horizontes; } \\
\checkmark & \text { mostrou que a leitura desencadeia o raciocínio, } \\
& \text { melhorando a escrita; } \\
\checkmark & \text { superou as expectativas de muitos participantes; } \\
\checkmark & \text { criou “oportunidades e possibilidades múltiplas } \\
\text { de expansão de conhecimentos, de troca de } & \text { vivências, experiências, informações...”; } \\
\checkmark & \text { acrescentou um novo olhar ; } \\
\checkmark & \text { constituiu-se em uma “oportunidade excelente de } \\
\text { enriquecer nosso saber, de forma inteligente, } \\
\text { criativa e, principalmente, saborosa”; } \\
\checkmark \quad \text { “... me aguçou a vontade de ler de outras formas, } \\
\text { compreendi que antes de escrever é preciso ter } \\
\text { interesse pelo assunto”; } \\
\checkmark \quad \text { “Acho que este foi um dos poucos cursos que fiz } \\
\text { em que me senti muito à vontade para perguntar } \\
\text { e fazer observações”; } \\
\checkmark \quad \text { "Foi ótimo! Professoras, ambiente físico, os } \\
\text { lanches, os colegas; horário e duração bons”. }\end{array}$ & 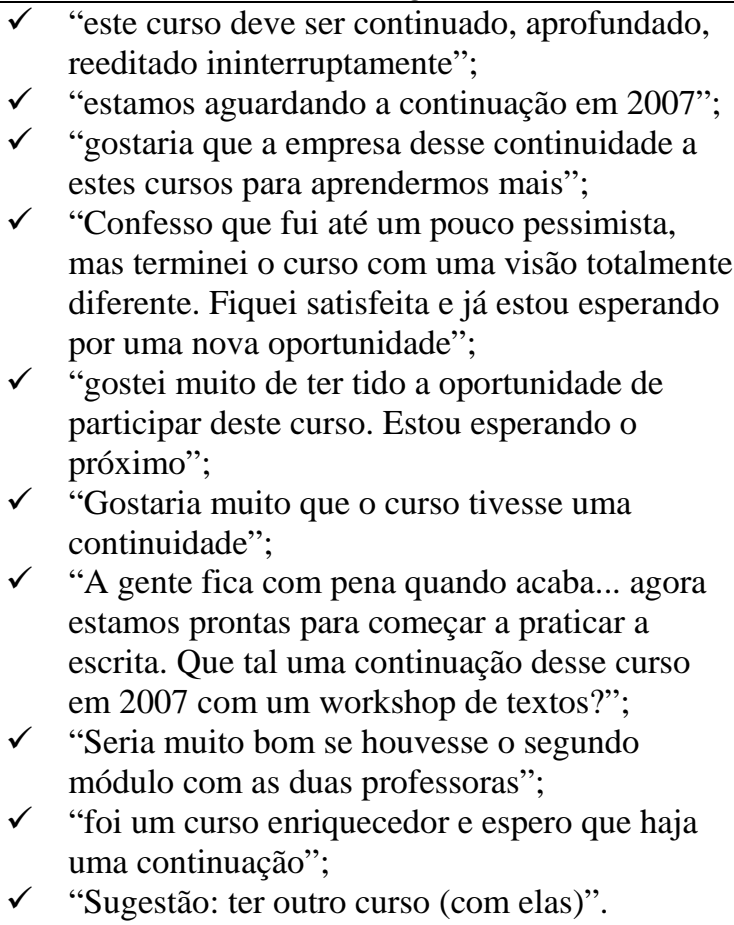 \\
\hline
\end{tabular}

Quadro 1. Apreciações, relatos e sugestões dos alunos do Serviço Social do Comércio.

Sempre acreditamos que a origem da palavra “aluno” não tem sua razão de ser considerando-o como "sem luz" - porque todos aqueles que se propõem a entrar em 
uma sala de aula em busca de (mais) conhecimento trazem consigo um acervo sóciohistórico-cultural constituído; e quando esse saber é considerado, o resultado é um entrelaçamento do conhecido e do novo, facilitando, assim, o estabelecimento de uma rede atada pelos nós da aprendizagem.

A segunda experiência se consistiu na elaboração de um projeto para um grupo específico da área do Direito. No curso, Direito - a Língua Portuguesa em sua defesa (duração de 30 horas), em 2007, os participantes tiveram a oportunidade de reconhecer o que é texto, contexto e intertextualidade e suas implicações na escrita.

Mesmo os diplomados e já atuando profissionalmente apresentam, em algumas situações, certa falta de intimidade com a linguagem e se deparam com dificuldades específicas no momento em que dependem de recursos da língua para algum fim prático. Os participantes, conscientes da necessidade de aprimoramento, buscaram no curso estímulo para melhorar sua produção de textos, o que foi desenvolvido por meio de jogos com a linguagem, aprofundando, assim, o interesse pelo processo de criação textual.

O curso permitiu também aguçar a percepção das relações entre linguagem verbal e não verbal, texto temático ou figurativo e os tipos de discurso, argumentação, coesão e coerência, concordância verbo-nominal, organização textual, estilo, texto acadêmico e “voz autorizada”, variação e preconceito linguísticos e tópico frasal. Consideramos o conhecimento desses temas como fundamental para toda e qualquer produção textual. Neste curso, todavia, o material de base usado tanto para exemplificação da parte teórica como para a prática de textos em sala, foi ancorado na área do Direito e nas dúvidas reais trazidas pelos participantes.

Para nós, profissionais da área da educação, foi um momento salutar em que alcançamos a meta almejada na relação ensino-aprendizagem, ou seja, a troca de conhecimentos. Por um lado, tivemos que enveredar pelos caminhos do Direito em busca de conhecimentos que dessem subsídios às nossas aulas e, por outro, a partir dos recursos linguísticos trabalhados com os participantes, foi possível considerar com apreço a aplicação dos conteúdos na área deles.

O terceiro relato refere-se à experiência com técnicos de uma empresa de processamentos de dados, no curso intitulado A Língua Portuguesa e a interação empresarial (duração de 30 horas), realizado em 2008. A razão do interesse pelo curso deu-se pela constatação de problemas de comunicação no interior da empresa, bem como entre funcionários e clientes. O desafio era, então, uma vez que o curso nos foi 
solicitado, primeiramente detectar os fatores que desencadeavam o problema e em seguida buscar meios para solucioná-los.

Tendo como base os tópicos citados acima, direcionamos os encontros para uma prática simulada em que os problemas eram expostos e, a partir dos conteúdos apontados, os alunos apresentavam uma situação-resposta.

Dentre as atividades textuais realizadas, podemos destacar: i) o envio de texto do cliente solicitando reparo e/ou assistência técnica e a resposta do funcionário usando uma linguagem apropriada à situação (convém mencionar que os técnicos tratavam indiferentemente seus colegas e seus clientes usando o mesmo jargão técnico); ii) exercício de adequação textual considerando o respeito à hierarquia na empresa, enfatizando que a mudança de suporte para circulação do texto não deve influenciar na formalidade ou informalidade que lhe é peculiar; iii) simulação de mensagens na comunicação entre funcionários.

A Língua Portuguesa extrapola os domínios da academia. Nessa prática vivenciada com profissionais que, de certa forma, dependiam de uma melhor comunicação para consolidar seus negócios, percebemos que a habilidade de manusear as palavras é de suma importância para o bom desempenho de uma empresa.

Diferente de todas as experiências relatadas anteriormente, em que a prática de interação era o alvo, no caso que relataremos a seguir é a situação que serve como base para se criar um espaço de reflexão sobre linguagem, com a finalidade de aprimoramento acadêmico. Nesse curso, Itinerários Linguísticos (40 horas), também ocorrido em 2008, tendo um público-alvo com domínio metalinguístico, demos enfoque diferenciado aos aspectos da língua e da linguagem. As teorias linguísticas serviram de ponte para reavaliar as práticas pedagógicas e a própria pesquisa, seja ela teórica ou empírica.

As aulas para esse público acadêmico foram desenvolvidas em grupos pequenos, em centros de estudos de línguas e estudos linguísticos. Dentre os que já participaram, grande parte o fez com o intuito de conseguir dar sequência a seus estudos na pósgraduação. Ao mesmo tempo em que o conteúdo teórico era ministrado, os alunos eram levados a relacionar esse conteúdo com o ensino e a pesquisa e, com isso, iam percebendo que há um vínculo indissociável entre esses domínios.

O aspecto mais relevante, sob nosso ponto de vista, é o fato de que o objetivo inicial nem sempre permaneceu até o final, o que denota que o conhecimento aprofundado leva a uma escolha mais consciente do espaço de aplicação da teoria 
apreendida. Gostaríamos de mencionar o caso de uma aluna que, após participar de três aulas, já tinha certeza de que não queria mais prosseguir nos estudos em nível de mestrado, mas que continuou o curso (vinte encontros) porque estava certa de que a reflexão linguística traria grandes contribuições para sua prática profissional.

\section{CONSIDERAÇÕES FINAIS}

Nossa experiência como alunas de uma escola embasada em exercícios metalinguísticos estruturais, capaz de transformar a língua viva em objeto estático de análise, instigou-nos, no decorrer de nossa formação acadêmica, a buscar um ensino de língua que não dissociasse o sujeito de sua linguagem. Manusear a língua tendo consciência de que ela é viva e constitutiva dos falantes é uma maneira de produzir novos efeitos de sentidos aplicados a cada situação do cotidiano.

O objetivo principal deste relato foi descrever uma verificação de que o domínio da língua portuguesa é imprescindível para que o falante possa exercer suas atividades profissionais, em diversas instâncias. Não desconsideramos, em nenhum momento, que a língua é constitutiva de todos os sujeitos, e é exatamente por isso que nos preocupamos em trabalhar com a LM de maneira que cada aluno se sinta um usuário dela e não escravo de suas normas.

Em tempos de ajuda especializada para as mais diversas atividades, como os personal trainers, personal dancers, personal stylists, por exemplo, podemos dizer que hoje em dia há campo para um novo tipo de profissional, aquele que ensina como usar melhor a linguagem. Em decorrência disso, nascem os cursos direcionados para cada tipo de profissão, considerando as necessidades do cotidiano de cada categoria.

É muito gratificante quando, algum tempo decorrido após o término de um curso desse tipo, recebemos mensagens de ex-alunos com sugestões de atividades e temas para nossos trabalhos futuros. Isso demonstra que eles adquiriram uma sensibilidade para perceber algo que antes não os instigava. Como ilustração, copiamos abaixo uma mensagem de uma ex-aluna do curso de Direito, recebida em 29/março/2009:

Queridas professoras, gostaria de parabenizá-las pelas tão frutíferas aulas ministradas. Essas aulas foram de grande importância para mim, pois obtive grande conhecimento. E é com muito carinho que envio este arquivo histórico que poderá servir-lhes como fonte para algum trabalho ou pesquisa. Beijos. V.G. [enviou arquivo em PowerPoint sobre a história de São Paulo, SP, - Memórias de uma grande cidade] 
Acreditamos que isso só é possível porque consideramos todo "a-luno” não como um ser "sem luz”, mas como alguém que tem conhecimentos preciosos e que precisa apenas de um ambiente propício para seu desenvolvimento e para um intercâmbio com seus interlocutores.

Uma constatação importante é que os conhecimentos teóricos são imprescindíveis, mas não se pode perder o elo com o fazer cotidiano. O professor deve primar em mostrar caminhos que levem a objetivos sempre maiores, não visando apenas o cumprimento de uma grade curricular. Além disso, o gosto pela pesquisa sendo estimulado promove o conhecimento além das expectativas ao envolver os aprendizes em novos desafios do dia-a-dia.

Dessa forma, o trabalho com a LM sob a perspectiva de que há, sim, uma finalidade no ensino da mesmo, responde aos alunos a pergunta "Para que estudar língua portuguesa?” Para :

\footnotetext{
$\checkmark$ nos constituirmos cidadãos em um país que prescreve suas leis (direitos e deveres) usando a norma culta;

$\checkmark$ termos habilidades linguísticas que nos permitam, além de criarmos sentidos na língua, refletir sobre os sentidos criados

$\checkmark$ aprimorarmos nosso conhecimento cultural, considerando que língua e cultura são intrínsecas;

$\checkmark$ termos um aprimoramento pessoal e profissional

$\checkmark \quad$...
}

\section{REFERÊNCIAS}

Bagno, M. (2008). Preconceito Linguístico - o que é e como se faz. 50ed. São Paulo: Edições Loyola.

Bakhtin, M. (1997). Estética da criação verbal. 2ed. Tradução de Maria Galvão Pereira. São Paulo: Martins Fontes.

Benveniste, E. (1995). Problemas de Linguística Geral I. Campinas: Pontes.

Genouvrier, E. \& Peytard, J. (1974). Linguística e ensino do português. Tradução de Rodolfo Ilari. Coimbra: Almedina.

Geraldi, J. W. (org.) (2000). O texto na sala de aula - Leitura \& Produção. Cascavel: ASSOESTE. 
Possenti, S. (2002). Por que (não) ensinar gramática na escola. Campinas - SP: Mercado das Letras: Associação de Leitura do Brasil.

Silva, R. V. M. e. (2004). O Português são dois: novas fronteiras, velhos problemas. São Paulo: Parábola Editorial.

\section{AS AUTORAS}

Maria Cristina Parreira da Silva é graduada em Licenciatura em Letras pela Universidade Estadual Paulista Júlio de Mesquita Filho (UNESP-IBILCE), Mestre e Doutora em Linguística e Língua Portuguesa pela UNESP-FCLar. Atuou como professora de Língua Materna por quatro anos em uma faculdade privada, ministrando aulas de Morfologia, Fonética-Fonologia, Lexicologia-Lexicografia. Tem experiência em pesquisa na área de Lexicologia e Lexicografia, Lexicografia Pedagógica, Ensino de Línguas Estrangeiras, Língua Francesa e Ensino de Línguas para Fins Específicos. É docente de Língua Francesa na graduação da UNESP-SJRP desde 2003 e na pósgraduação desde 2007. É líder do GAMPLE - Grupo Acadêmico Multidisciplinar: Pesquisa Lingüística e Ensino. Contato : (17) 3223-8855 / mcparreira2002@yahoo.com.br

Rosimar de Fátima Schinelo é graduada em Licenciatura em Letras pela Universidade Estadual Paulista Júlio de Mesquita Filho, UNESP-São José do Rio Preto, Mestre e Doutora em Linguística e Língua Portuguesa pela UNESP-Araraquara. Tem experiência na Área de Língua Portuguesa, Linguística e Educação, ministrando aulas e desenvolvendo pesquisas nos Cursos de Letras e Pedagogia. Atua como pesquisadora relacionando os seguintes temas: oralidade/escrita, ensino, formação de professores, léxico e discurso. Atualmente é professora da FATEC-Catanduva/SP, e membro do GAMPLE - Grupo Acadêmico Multidisciplinar: Pesquisa Linguística e Ensino. Contato : (17) 3216-7257 / rfs.daleth@terra.com.br 